\title{
A two stage model for moisture-induced deformations in expansive soils
}

\author{
Maki Ito ${ }^{1}$, Shahid Azam ${ }^{1 *}$ and Yafei $\mathrm{Hu}^{2}$
}

\begin{abstract}
Background: Moisture-induced suction changes in expansive soils due to infiltration and evaporation result in failure of civil infrastructure. The objective of this paper was to develop a two stage deformation model by simultaneously calculating soil suction and stress state. The model predictions were validated using a one-year field monitoring data.

Results: Deformations in expansive soils closely match cyclical suction changes corresponding to seasonal weather variations. Volume changes fluctuated close to the ground surface and gradually decreased with depth (overburden pressure) due to isolation from meteorological effects. The top $2 \mathrm{~m}$ depth was found to be the active zone susceptible to moisture variations.

Conclusions: The model agreed well with the monitoring data trends with deviations attributed to analytical assumptions in the equations, ineffective capture of antecedent soil conditions, possible soil heterogeneity and anisotropy, and hysteresis in soil saturation and desaturation.
\end{abstract}

Keywords: Numerical modeling; Unsaturated soils; Expansive soils; Swelling; Shrinking

\section{Background}

Expansive soils exhibit volumetric deformations when their water content changes. The moisture flux is governed by climatic conditions prevalent in an area. In arid and semi-arid regions of the globe, where most expansive soils occur, the moisture loss through evaporation generally exceeds the moisture gain through precipitation thereby rendering the soil unsaturated. Consequently, the soil undergoes swelling due to rainfall and shrinkage between successive rainfall events. The effect of these alternate movements exhibits differently under various types of covers. For example, longitudinal cracks in highway embankments (Jotisankasa et al. 2011), heaved domes in residential basements (Ito and Azam 2013), settlement in the vicinity of trees (Driscoll 1983), and vegetation induced movements in pipelines (Clayton et al. 2010). The cost of infrastructure repair is comparable to other natural disasters such as the estimated $\$ 1$ billion in the United States of America (Phanikumar and Sharma 2006).

\footnotetext{
* Correspondence: Shahid.Azam@URegina.CA

${ }^{1}$ Environmental Systems Engineering, Faculty of Engineering and Applied Science, University of Regina, 3737 Wascana Parkway, Regina, SK S4S 0A2, Canada

Full list of author information is available at the end of the article
}

Few investigations have been reported on the field behavior of expansive clays. Zhan et al. (2007) analyzed infiltration through a grassed expansive soil slope in Zaoyang, Hubei, China that was subjected to artificial rainfall. Likewise, Fityus et al. (2004) summarized a seven year monitoring data highlighting the effect of soil covers and trees on volume changes in expansive soils at a test site near New Castle, Australia. Finally, $\mathrm{Hu}$ et al. (2010) presented a one-year field data at a water distribution pipe site in the expansive soil deposit of Regina, Saskatchewan, Canada. The scarcity in reported case histories is because such undertakings are time consuming, labour intensive, and quite costly. The above-mentioned issues can be addressed through the alternative approach of numerical modeling.

Roscoe et al. (1958) developed the Original Cam Clay Model (OCCM) for saturated soils. Utilizing the constitutive stress-strain relationships, the elasto-plastic constitutive model consists of the following pillars: (i) elastic property; (ii) yield surface; (iii) plastic potential; and (iv) hardening rule. Roscoe and Burland (1968) subsequently modified the original model by incorporating elastic shear strains and an improved yield

\section{空}

(c) 2014 Ito et al.; licensee Springer. This is an Open Access article distributed under the terms of the Creative Commons Attribution License (http://creativecommons.org/licenses/by/4.0), which permits unrestricted use, distribution, and reproduction in any medium, provided the original work is properly credited. 
surface. To capture the behavior of unsaturated soils, Alonso et al. (1990) developed the Barcelona Basic Model (BBM) by correlating soil hardening with suction. Alonso et al. (1999) extended the above model to expansive soils by including a conceptual fabric representation: elastic deformations in microstructure and plastic deformations in macrostructure (Gens and Alonso 1992). The Barcelona Expansive Model (BExM) was validated using laboratory test data to understand the combined effect of vertical stress and soil suction on net volumetric strains. Farulla et al. (2007) confirmed that the BExM model predicts the behaviour of fissured clays possessing dual porosity. These authors concluded that successive swell-shrink cycles gradually reduce plastic strains thereby converting the soil to an elastic medium.

$\mathrm{Vu}$ and Fredlund (2004) developed an elasticity based vertical displacement model for unsaturated expansive soils. The nonlinear strain was accounted for by using the coefficient of compressibility as a function of net normal stress and soil suction. The model is appropriate for predicting monotonic paths of the above two stress state variables. Adem and Vanapalli (2013) proposed the Modulus of Elasticity Based Method (MEBM) for deformation prediction in similar soils by using a semi-empirical estimation of the modulus of elasticity (Vanapalli and Oh 2010) along with transient changes in soil suction (Wilson 1997). The overestimated vertical displacement in this model is attributed to the one-dimensionality and considering soil suction as the only stress state variable.

Derived from Ito and $\mathrm{Hu}$ (2011), this study develops a two-dimensional model (by including lateral volume changes in calculating vertical deformations) that captures normal stress (overburden soil pressure) and soil suction (net atmospheric flux). The current work is based on a one-dimensional soil atmosphere model where the swelling potential was determined using laboratory test results (Azam and Ito 2012). The two-dimensional nature of the present model helps improve the capture of actual field conditions. This was confirmed through model validation using field monitoring data, reported by $\mathrm{Hu}$ et al. (2010).

The objective of this paper was to develop a two stage model for moisture-induced deformations in expansive soils. This included a coupled soil-atmosphere model for seepage through the soil that generated suction data and suction-based displacement model that takes into account the effect of overburden soil pressure. The predicted results were validated using a one-year field instrumentation data.

\section{Results and discussions}

Figure 1 gives the variation in soil suction at selected depths with respect to time. At the ground level, the exposed surface showed median suction values of 2000 $\mathrm{kPa}$ (variation of $\pm 500 \mathrm{kPa}$ ) from May through August,
$1500 \mathrm{kPa}$ (variation of $\pm 500 \mathrm{kPa}$ ) from September through October, $1400 \mathrm{kPa}$ (negligible variation) from November through February, and $1400 \mathrm{kPa}$ (variation of $\pm 200 \mathrm{kPa}$ ) from March through April. These cyclical suction changes correlated well with the seasonal weather conditions, that is, multiple rainfall events during summer and fall, snow accumulation during winter, and snowmelt and rainfall during spring. Conversely, the median suction values for the covered surface were $1600 \mathrm{kPa}$ (variation of $\pm 100 \mathrm{kPa}$ ) from May through August and remained at about 1400 $\mathrm{kPa}$ for the rest of the year. The significantly lower suction variations correspond to the isolation of the soil from seasonal weather patterns. At $2 \mathrm{~m}$ depth, the exposed surface showed median suction values of $1600 \mathrm{kPa}$ (variation of $\pm 50 \mathrm{kPa}$ ) from May through August, 1500 $\mathrm{kPa}$ (variation of $\pm 50 \mathrm{kPa}$ ) from September through October, $1350 \mathrm{kPa}$ (negligible variation) from November through April. Conversely, the median suction values for the covered surface were $1300 \mathrm{kPa}$ (variation of $\pm 50 \mathrm{kPa}$ ) from May through November and remained at about $1250 \mathrm{kPa}$ for the rest of the year. The suction decrease and the low suction variation are attributed to steady-state moisture flow (the effect of seasonal weather variations is reduced) at increased depth (Lu and Likos 2004).

Figure 2 gives the effect of weather conditions on soil deformation at selected depths $(0 \mathrm{~m}, 0.5 \mathrm{~m}, 1 \mathrm{~m}$, and $2 \mathrm{~m})$ during the year for exposed ground. The average vertical soil deformations corresponded well with precipitation, evaporation, and net flux data. The surface layer at an initially unsaturated state $(2000 \mathrm{kPa} \pm 500 \mathrm{kPa})$ imbibed water made available from May through August by rainfall events and lost that water between consecutive rainfall events. The maximum daily heave and settlement were predicted to be $4 \mathrm{~mm}$ and $-1 \mathrm{~mm}$, respectively. The higher daily heave is attributed to the relative ease of downward seepage compared to the more energy intensive evaporation process causing settlement (van de Griend and Owe 1994). The corresponding daily deformations remained similar during September through October because of similar variation in suction. The ground movements were negligible during winter (November through February) because precipitation was primarily received as snow that did not flow through the soil and covered the soil from any possible evaporation. Soil deformations were found to be in the order of $2 \mathrm{~mm}$ to $-1 \mathrm{~mm}$ (corresponding to suction variations of $1400 \mathrm{kPa} \pm 200 \mathrm{kPa}$ ) during March through April because of snowmelt and rainfall events. The fluctuations in daily soil deformations gradually decreased with depth and were found to be negligible at $2 \mathrm{~m}$ below the ground. This progressive reduction in deformation is attributed to the overlying soil providing a cover (isolation from climatic conditions) and overburden load (cancelling the swelling movement). The model predictions indicate that the 


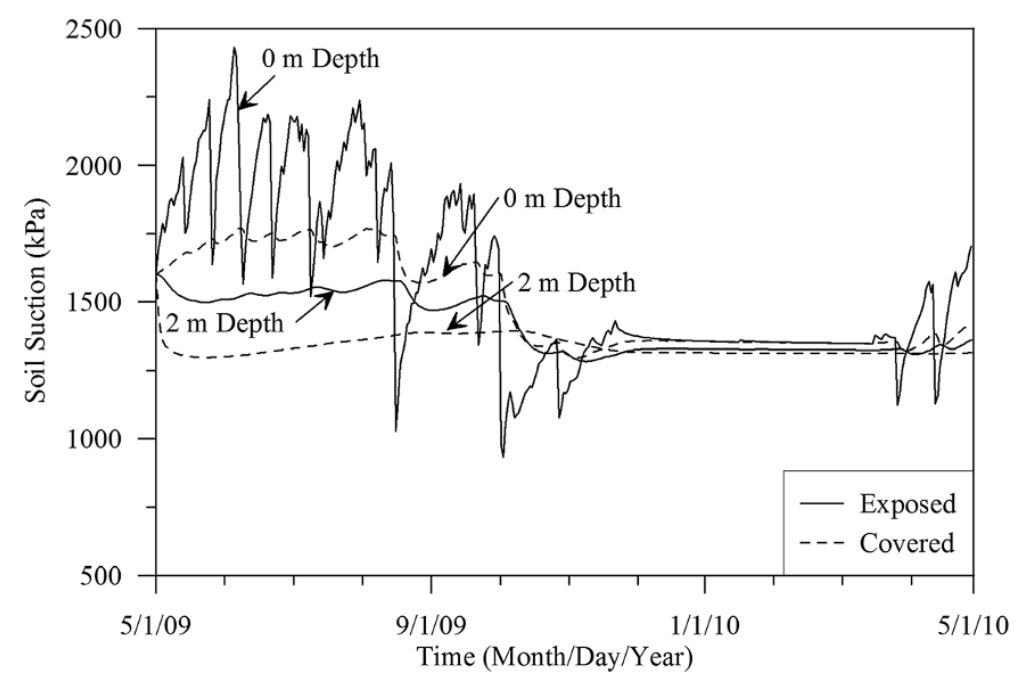

Figure 1 Suction variation versus time (modified after Ito and $\mathrm{Hu}, 2011$ ).

$2 \mathrm{~m}$ depth is the active zone where soil deformations are governed by change in atmospheric conditions.

Figure 3 illustrates the influence of cyclic weather variations on soil deformation at selected depths $(0 \mathrm{~m}, 0.5 \mathrm{~m}$, $1 \mathrm{~m}$, and $2 \mathrm{~m}$ ) during the year for covered ground. As expected, the effect of precipitation, evaporation, and net moisture flux on average vertical soil deformations was subdued because the overlaying soil layer that covered the lower layers of the deposit reduced moisture intake. The resulting maximum daily heave and settlement were predicted to be $0.7 \mathrm{~mm}$ and $-0.3 \mathrm{~mm}$, respectively.

Figure 4 gives the cumulative vertical soil displacement at the surface versus time. The model predicts that the exposed soil settled by $10 \mathrm{~mm}$ from May through August with spikes corresponding to weather conditions. The overall settlement during the summer months is attributed to the net water deficit in the area. This trend was reversed in September through October due to several heavy rainfall events where the soil bounced back to almost the original ground level. The alternate vertical displacement during the fall months were predicted to be $\pm 10 \mathrm{~mm}$. Insignificant soil movements occurred from November through February due to the above mentioned reasons. The cyclic vertical displacements were reactivated from March through April by spring snow melt and rainfall (causing a heave of up to $3 \mathrm{~mm}$ ) and evaporation causing shrinking of up to $5 \mathrm{~mm}$. Similar soil vertical displacements albeit at a reduced level was predicted for the covered surface.

The model predictions generally correlated well with the measured trends in data at the investigated site (obtained from $\mathrm{Hu}$ et al. 2010). The variations between the predicted and the measured data are attributed to the following: (i) analytical assumptions in the equations for calculating net flux; (ii) ineffective capture of antecedent weather conditions by the model; (iii) possible soil heterogeneity, anisotropy, and vegetation at the investigated site; (iv) hysteresis in soil saturation and desaturation during the year; and (v) lack of meterological data at the investigated site.

\section{Conclusions}

Moisture-induced deformations in expansive soils are governed by the net flux at the soil-atmosphere interface and by the suction regime within the soil deposit. A two-stage two-dimensional model was developed. The model predictions generally correlated well with the trends in monitoring data at the investigated site. Deformations in expansive soils closely match cyclical suction changes corresponding to seasonal weather variations. Volume changes fluctuated widely close to the ground surface and gradually reduced with depth due to isolation from meteorological parameters and overburden pressure. The top $2 \mathrm{~m}$ depth was found to be the active zone susceptible to moisture variations. The variations between the predicted and the measured data are attributed to analytical assumptions in the equations for calculating net flux, ineffective capture of antecedent soil conditions by the model, possible soil heterogeneity, anisotropy, and vegetation at the investigated site, hysteresis in soil saturation and desaturation during the year, and lack of meteorological data at the investigated site. Clearly, the current model depends on an effective capture of site conditions and material properties.

\section{Methods \\ Modeling process}

Figure 5 describes the soil-atmosphere/soil-deformation modeling process. First, a two-dimensional soil-atmosphere 


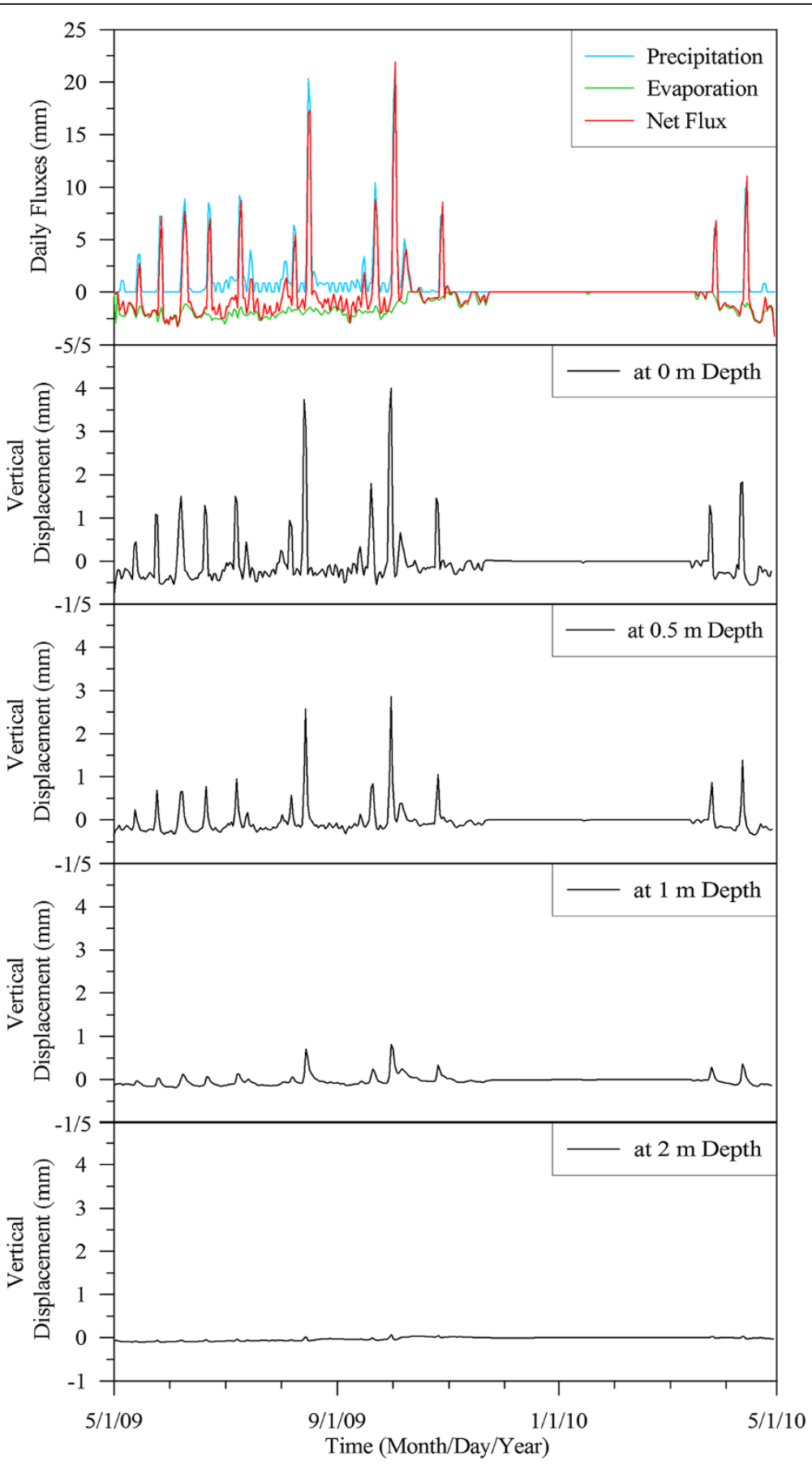

Figure 2 Predicted soil deformations under exposed surface.

model required two input categories, namely: soil properties and atmospheric parameters. The soil properties consisted of SWCC and hydraulic conductivity functions. The $S W C C$ was estimated by using SoilVision software based on measured index properties ( $w, G s$, and $\left.\gamma_{d}\right)$ and a grain size distribution (GSD) curve. Similarly, using the saturated hydraulic conductivity $k_{s}=4.22 \times 10^{-9} \mathrm{~m} / \mathrm{s}$
(Shah 2011), the estimated hydraulic conductivity function $(k(\psi))$ was calculated. The climate data provided the infiltration and exfiltration fluxes to determine the boundary condition and then the net flux was calculated in relation to soil properties to obtain a suction profile. The complete theoretical details of the soil-atmospheric modeling process are described by Azam and Ito (2012). 


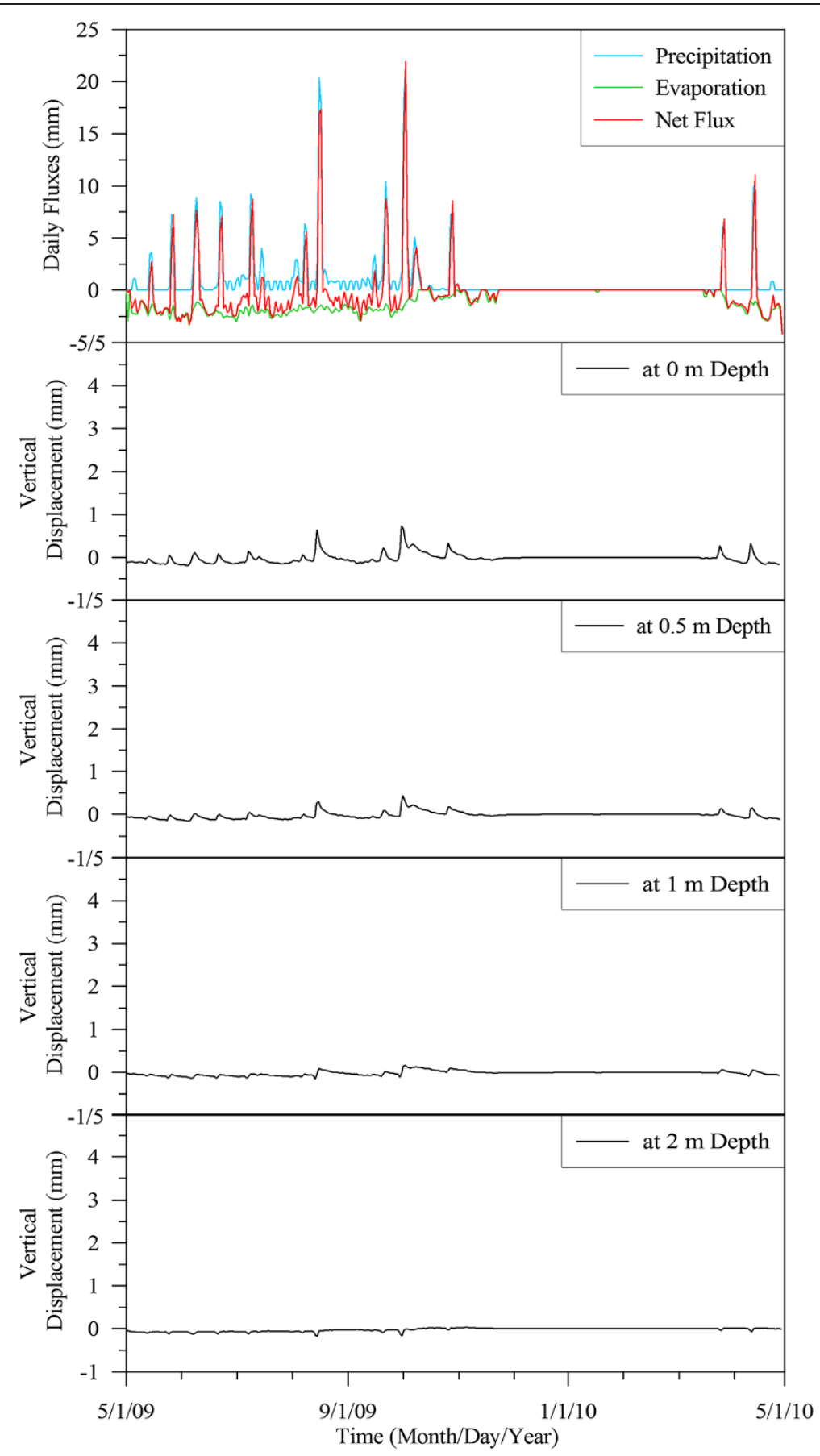

Figure 3 Predicted soil deformations under covered surface.

The soil deformation behaviour relative to the change in atmospheric conditions was predicted by using the concept of two independent stress state variables: net normal stress, $\left(\sigma-u_{a}\right)$ and matric suction, $\left(u_{a}-u_{w}\right)$, where $\sigma$ is the total stress, $u_{a}$ is pore-air pressure, and $u_{w}$ is pore-water pressure (Fredlund and Morgenstern 1977). The two-dimensional soil deformation analysis required soil elasticity parameters, namely: $E$, soil elasticity with respect to net normal stress and $H$, soil elasticity with respect to matric suction (Fredlund and Rahardjo 1993). The volume change index $C_{s}$ (obtained from the net normal stress plane) was obtained from the consolidation curve (Ito and Azam 2009). Likewise, $C_{m}$ (obtained from the matric suction plane) was obtained from the $S W C C$ 


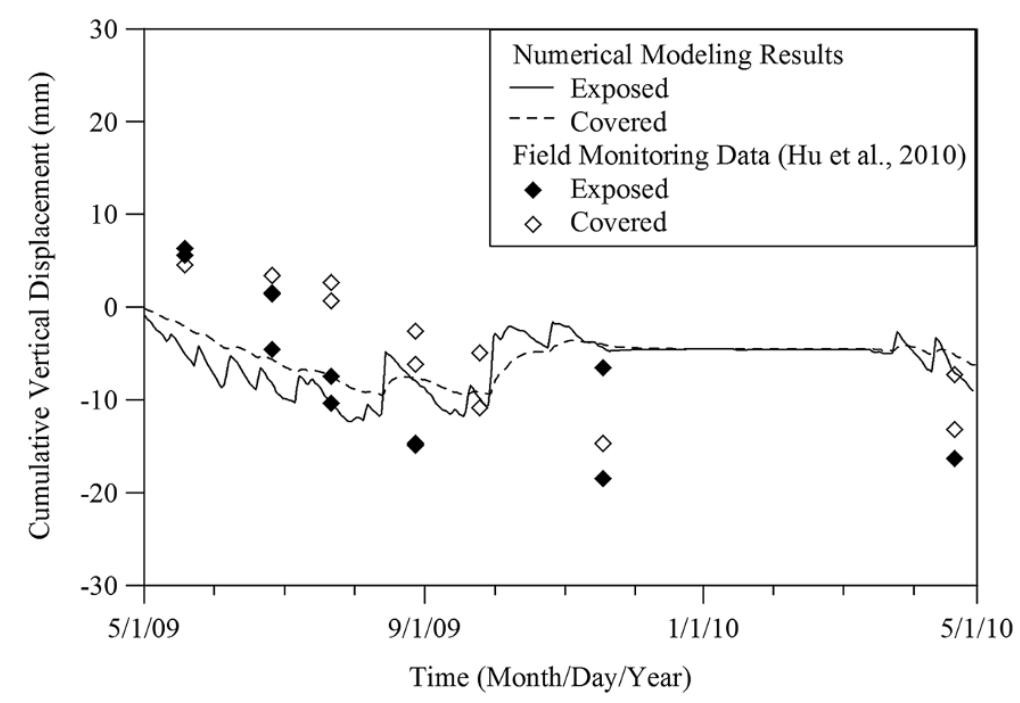

Figure 4 Comparison of modeled and monitored data.

and the shrinkage curve (Ito and Azam 2013). The elasticity parameters for both the net normal stress plane and the matric suction plane were calculated using a Poisson's ratio $\mu$ (estimated from the typical values of similar soils) for the soil structure as follows (Vu and Fredlund 2004):

$$
\begin{aligned}
& E=\frac{4.605(1+\mu)(1-2 \mu)\left(1+e_{0}\right)}{C_{s}}\left(\sigma-u_{a}\right) \\
& H=\frac{4.605(1+\mu)\left(1+e_{0}\right)}{C_{m}}\left(u_{a}-u_{w}\right)
\end{aligned}
$$

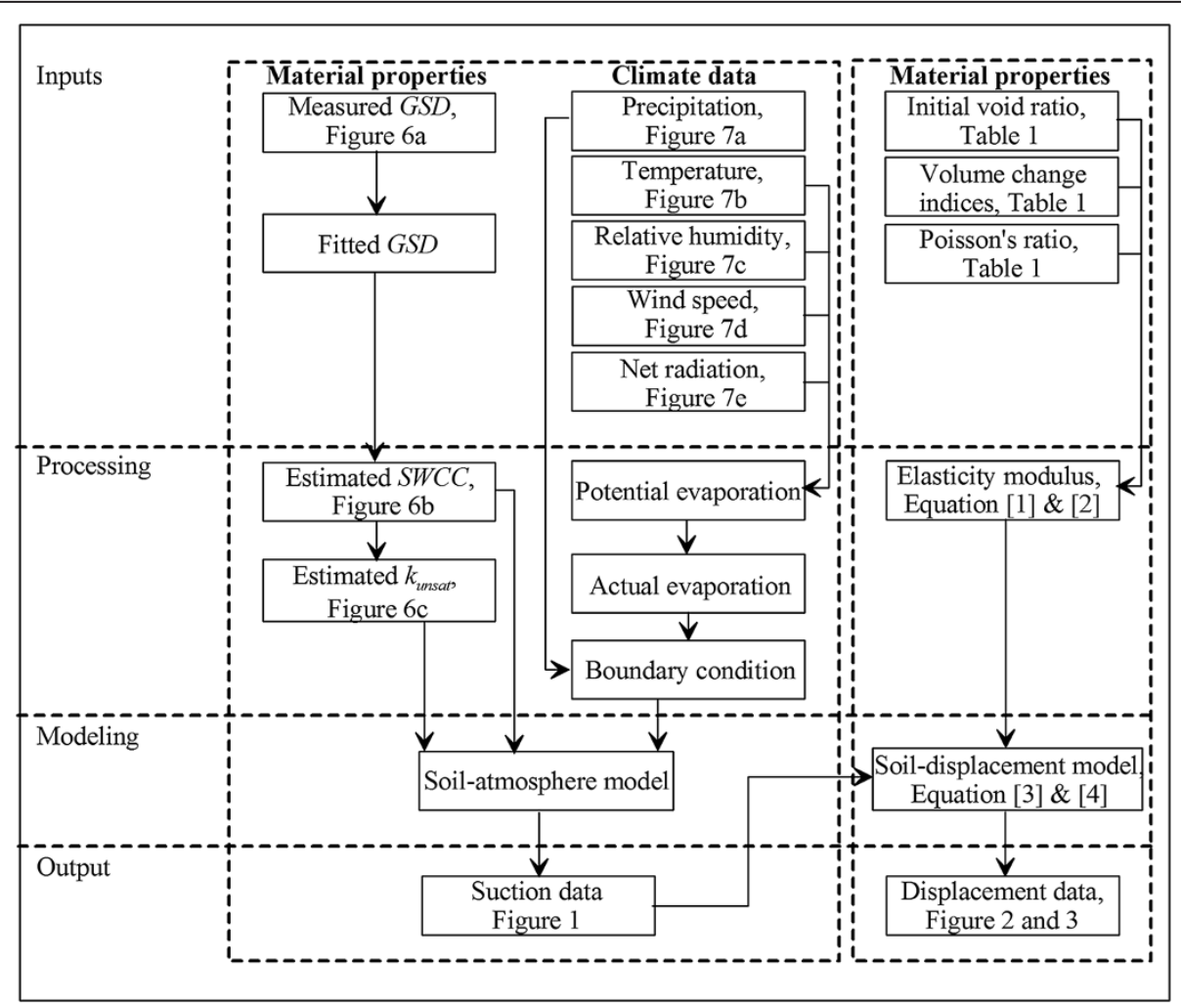

Figure 5 Modeling process (modified after Ito and $\mathrm{Hu}, 2011$ ). 
The net normal stress acting on a model profile before applying the weather conditions is the total vertical stress resulted from the overburden pressure. The applied atmospheric conditions adjust the void ratio along with the matric suction plane and the maximum variations in water content from full saturation to desiccation
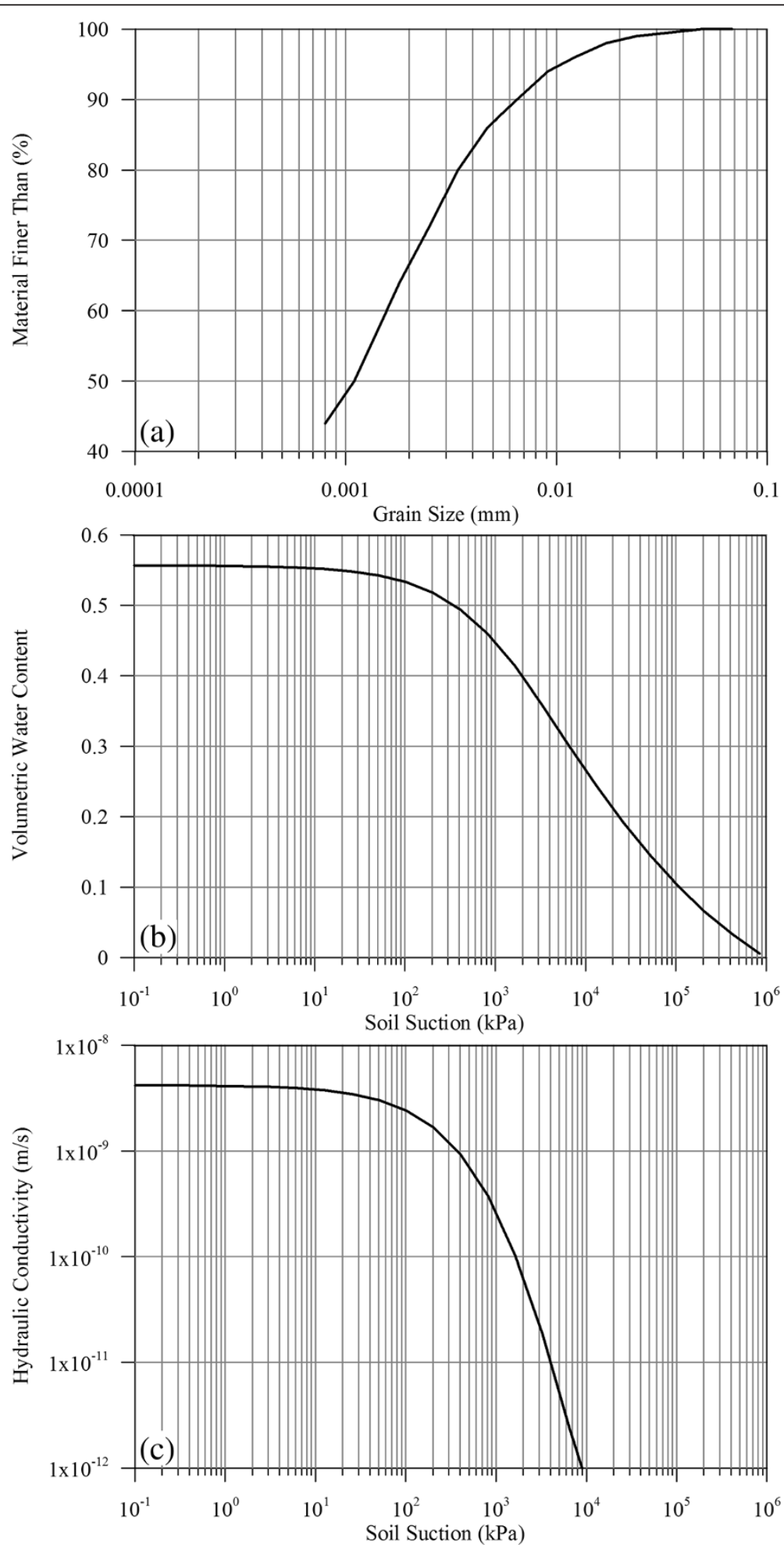

Figure 6 Material properties: (a) grain size distribution, (b) soil water characteristics curve, (c) hydraulic conductivity function. 
gives about $5 \mathrm{kPa} / \mathrm{m}$ stress difference, but it is almost equalized by daily fluctuations. Due to negligible variation in net normal stress state induced by the water content change, the model solely captured the simultaneous cancellation of swelling with the overburden pressure.

Soil deformations in vertical and horizontal directions was solved in accordance with the following governing equation relative to the soil suction change (Fredlund and Vu 2003):

$$
\begin{aligned}
& \frac{\partial}{\partial x}\left\{C\left[(1-\mu) \frac{\partial u}{\partial x}+u \frac{\partial v}{\partial y}-\frac{(1+\mu)}{H}\left(u_{a}-u_{w}\right)\right]\right\} \\
& \quad+\frac{\partial}{\partial y}\left\{G\left(\frac{\partial v}{\partial x}+\frac{\partial u}{\partial y}\right)\right\}=0 \\
& \frac{\partial}{\partial x}\left\{G\left(\frac{\partial v}{\partial x}+\frac{\partial u}{\partial y}\right)\right\} \\
& \quad+\frac{\partial}{\partial y}\left\{C\left[\mu \frac{\partial u}{\partial x}+(1-\mu) \frac{\partial}{\partial y}-\frac{1-\mu}{H}\left(u_{a}-u_{w}\right)\right]\right\} \\
& \quad+p g=0
\end{aligned}
$$

where, $p$ is density of soil, $g$ is acceleration due to gravity, $C=E /(1-2 \mu)(1+\mu)$, and $G=E / 2(1+\mu)$.

The model consisted of a homogeneous soil deposit having a $6 \mathrm{~m}$ wide $\mathrm{x} 4 \mathrm{~m}$ deep geometry. To understand the effect of meteorological conditions on the soil deposit, one half of the top boundary was treated as the exposed surface (closely mimicking the vegetated park) and the other half was considered to be the covered surface (pertaining to the asphalt-pavement) at the investigated site. Zero water flux was applied at the bottom boundary to represent no ground water table at $15 \mathrm{~m}$ depth at the investigation site. Daily climate data from May 1, 2009 to April 30, 2010 was obtained from the Regina International Airport weather station (located about $3 \mathrm{~km}$ from the investigation site). An initial matric suction of $1600 \mathrm{kPa}$ based on the field measurement reported by $\mathrm{Vu}$ et al. (2007) was used. In the soildeformation model, free movements of soil in the vertical direction were allowed at the top boundary and the horizontal directions were fixed. Likewise, the lower boundary was fixed in both directions.

A general purpose partial differential equation solver, FlexPDE was used for the analysis. The solver utilized the finite element method generating a triangular mesh over a two dimensional geometry. The adequacy of the mesh was constantly calculated and the automatic mesh refinement feature of the solver was applied to reduce error within a tolerance of 0.001 . Using the script editor, the governing equation and material properties were directly input in the model compiler. An equation analyzer expanded the defined equation and the material properties, performed spatial differentiation, and applied integration by parts thereby reducing second order terms to create symbolic Galerkin equations for use in the weighted residual method. The Galerkin equations were further differentiated to form the Jacobian coupling matrix for improved convergence. Likewise, the solution curvature was also calculated to include time integration for better accuracy. The model outputs were in the form of soil suction $(\mathrm{kPa})$ and vertical deformation $(\mathrm{mm})$ for the soil-atmosphere model and the soil-deformation model, respectively.

\section{Material properties}

Borehole drillings were made in July 2006 and May 2009 at Cross place, Regina, and the materials used for this numerical modelling had been investigated by Azam et al. (2013). Figure 6(a) shows the grain size distribution curves for a sample obtained in May 2009. To avoid high complexity of numerical modelling, soil properties of a representative sample were used to represent a clay deposit in the model.

Figure 6(b) indicates the estimated SWCC. The curve exhibited the desaturation typical of fine-grained soils comprises of gradual decrease in the gravimetric moisture content as soil suction increases due to the presence of small pore spaces. Figure 6(c) shows the hydraulic conductivities as a function of soil suction. The curve also well captured the pore-size distribution derived from the grain size distribution curve shown in Figure 6(a). The reduction in hydraulic conductivity occurred slowly for the investigated clay and it only started to deviate from the saturated hydraulic conductivity value at a suction value around $100 \mathrm{kPa}$. Table 1 presents the soil properties used for the soil-deformation analysis. The elasticity parameter functions for the soil were calculated from equation [1] and [2] by using the volume change indices $C_{s}$ (from net normal stress plane) and $C_{m}$ (from matric suction plane) and an assumed Poisson's ratio.

\section{Climate data}

Figure 7 shows the meteorological parameters used for this numerical model from May 1, 2009 to April 30, 2010. With minor variations, the data generally followed the

\section{Table 1 Summary of soil properties}

\begin{tabular}{ll}
\hline Soil property & Value \\
\hline Dry unit weight, $\gamma_{d}\left(\mathrm{kN} / \mathrm{m}^{3}\right)$ & 12.0 \\
Initial void ratio, $e_{0}$ & 1.2 \\
Saturated volumetric moisture content $(\%)$ & 0.56 \\
Hydraulic conductivity, $k_{\text {sat }}(\mathrm{m} / \mathrm{s})$ & $4.22 \times 10^{-9}$ \\
Swelling index with respect to net normal stress, $C_{s}$ & 0.09 \\
Swelling index with respect to matric suction, $C_{m}$ & 0.1 \\
Poisson's ratio, $\mu$ & 0.33 \\
\hline
\end{tabular}



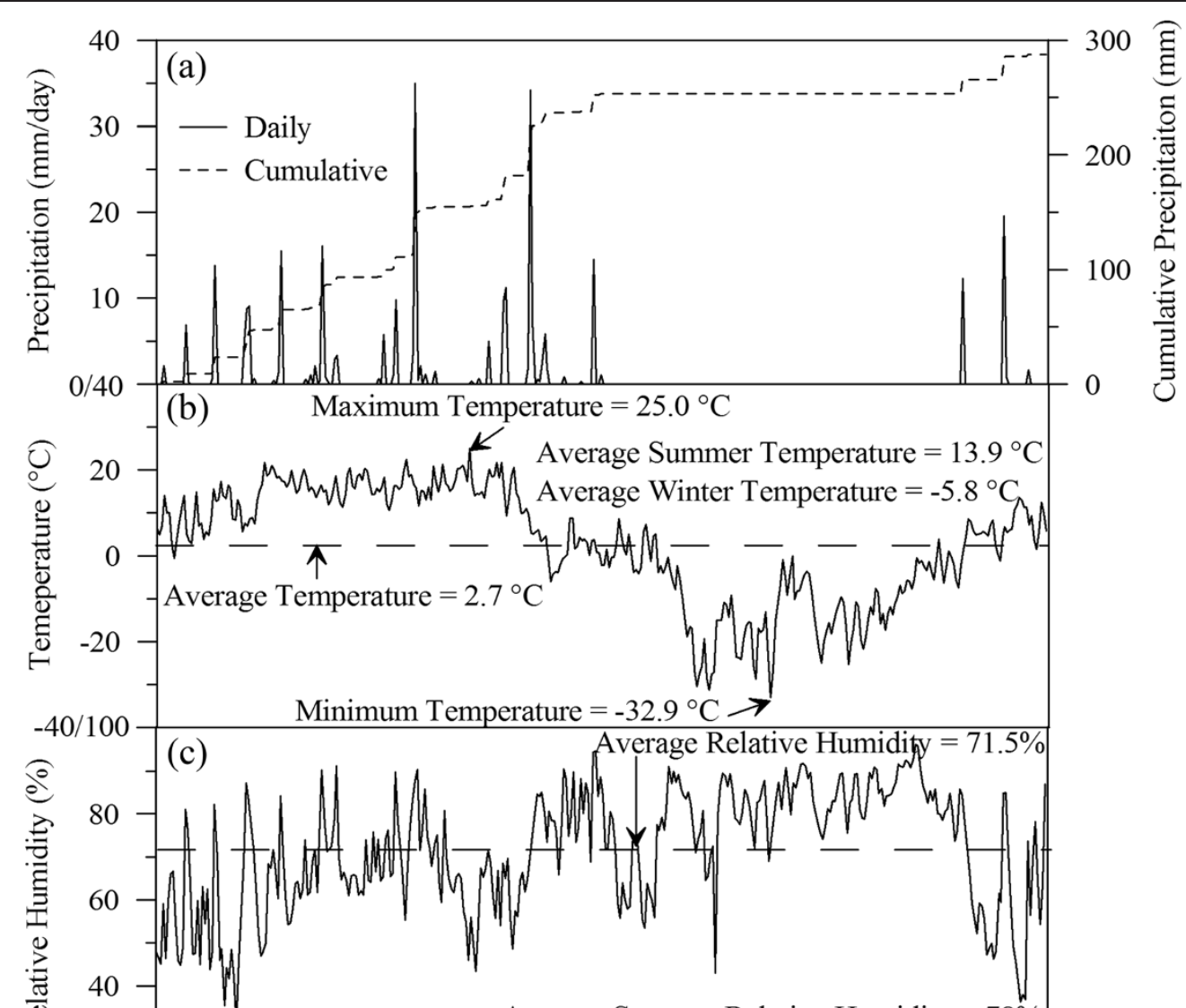

Average Summer Relative Humidity $=78 \%$

20/60 \begin{tabular}{rr} 
Average Winter Relative Humidity $=64 \%$ \\
\hline
\end{tabular}

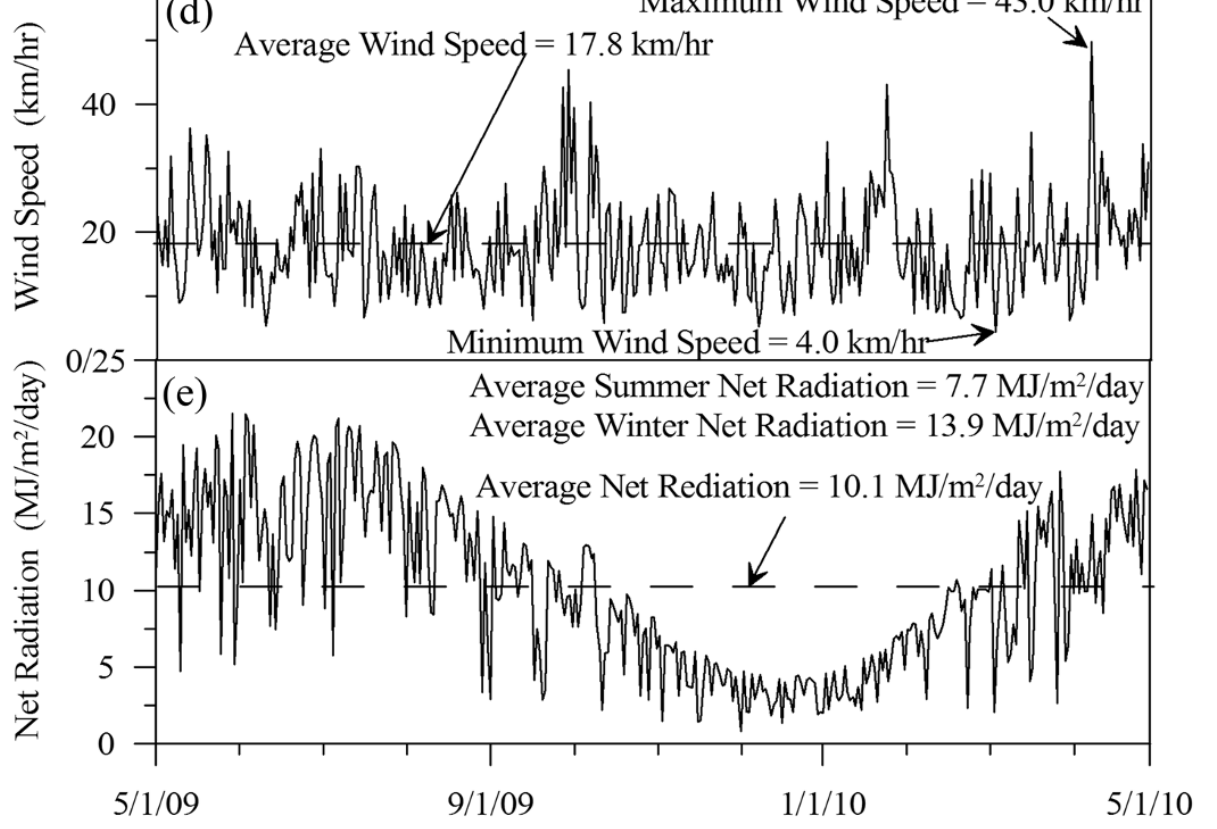

Time (Month/Day/Year)

Figure 7 Climate data: (a) precipitation; (b) temperature; (c) relative humidity; (d) wind speed; (e) net radiation. 
long-term average values for the area that is classified as a semi-arid zone (BSk) according to the Köppen Climate Classification System (McKnight and Hess 2001). Figure 7 (a) presents daily precipitation along with the cumulative values. The total precipitation was recorded to be $288 \mathrm{~mm}$. Rainfall primarily occurred during the summer and fall months with sporadic storm events. The accumulated snow $(12 \mathrm{~mm})$ gradually melted in early spring and the process was completed on March 27, 2010, when the mean temperature peaked to $1.4^{\circ} \mathrm{C}$ and remained above freezing for most of the day. Figure 7(b) shows the daily mean temperature. The annual mean temperature was found to be $2.7^{\circ} \mathrm{C}$. The average from May to September was $14.4^{\circ} \mathrm{C}$ and the average from October to April was $-5.8^{\circ} \mathrm{C}$. The maximum difference between the high and low temperatures was $57.9^{\circ} \mathrm{C}$. Relative humidity and wind speed data are shown in Figure $7(\mathrm{c})$ and (d), respectively. The relative humidity data was generally inversely proportional to the temperature data. The average of relative humidity in winter was $78 \%$ and reduced to $64 \%$ in the summer. There was no clear trend for wind speed - it changed regardless of the season. The daily net radiation was estimated in Figure 7(e) from the solar radiation measurement from November 1, 1999 to October 31, 2000 recorded in Swift Current, SK, by using albedo values of 0.1 for the period from November 1 to March 31 and 0.3 for the rest of the year.

The above data implies that during the summer time, the average temperature remained high $\left(14.4^{\circ} \mathrm{C}\right)$, the average wind speed was consistent $(17.8 \mathrm{~km} / \mathrm{hour})$, the average relative humidity was low (64\%), and the average net radiation was high $\left(13.9 \mathrm{MJ} / \mathrm{m}^{2} /\right.$ day $)$. Such conditions generally render the surface layer of Regina clay desiccated. Therefore, in any sporadic rainfall event during the summer, the expansive clay can readily adsorb all of the available water thereby resulting in swelling.

\section{Competing interests}

The authors declare that they have no competing interests.

\section{Authors' contributions}

Ml carried out numerical modelling and drafted the manuscript. SA provided conceptual guidance and polished the manuscript. YH reviewed and polished the manuscript. All of the authors read and approved the final manuscript.

\section{Acknowledgement}

The authors would like to acknowledge for the financial support provided by the Communities of Tomorrow Inc. Sincere thanks to Dr. Hung Vu and Mr. Imran Shah for their help during numerical modeling and soil data collection, respectively.

\section{Author details}

${ }^{1}$ Environmental Systems Engineering, Faculty of Engineering and Applied Science, University of Regina, 3737 Wascana Parkway, Regina, SK S4S 0A2, Canada. ${ }^{2}$ Infrastructure Planning Branch, Community Planning and Development Division, City of Regina, 2476 Victoria Avenue, Regina, SK S4P 3 C8, Canada.
Received: 15 March 2014 Accepted: 3 June 2014

Published: 24 June 2014

\section{Reference}

Adem H, Vanapalli S (2013) Constitutive modeling approach for estimating 1-D heave with respect to time for expansive soils. Int J Geotech Eng 7(2):199-204

Alonso E, Gens A, Josa A (1990) A constitutive model for partially saturated soils. Geotechnique 40(3):405-430

Alonso E, Vaunat J, Gens A (1999) Modelling the mechanical behaviour of expansive clays. Eng Geol 54:173-183

Azam S, Ito M (2012) Coupled soil-atmosphere modeling for expansive Regina clay. J Environ Inform 19(1):20-29

Azam S, Shah I, Raghunandan M, Ito M (2013) Study on swelling properties of an expansive soil deposit in Saskatchewan, Canada. B Eng Geol Environ 72(1):25-35

Clayton CRI, Xu M, Whiter JT, Ham A, Rust M (2010) Stresses in Cast-Iron Pipes due to Seasonal Shrink-Swell of Clay Soils. In: Proceedings of the Institution of Civil Engineers: Water Management, Vol. 163, No. 3, pp. 157-162

Driscoll R (1983) The influence of vegetation on the swelling and shrinkage of clays in Britain. Geotechnique 33(2):93-105

Farulla CA, Ferrari A, Romero E (2007) Mechanical Behaviour of Compacted Scaly Clay. In: Schanz T (ed) Experimental Unsaturated Soil Mechanics:112 Proceeding in Physics. Springer, NewYork, pp 345-354

Fityus S, Smith D, Allman M (2004) Expansive soil test site near Newcastle. J Geotech Geoenviron Eng 130(7):686-695

Fredlund D, Morgenstern N (1977) Stress state variables for unsaturated soils. J Geotech Eng 103:447-466

Fredlund D, Rahardjo H (1993) Soil Mechanics for Unsaturated Soil. John Wiley \& Sons, NewYork

Fredlund D, Vu H (2003) Numerical Modeling of Swelling and Shrinkage Soils Around Slab-on-Ground. In: PTI Conference, 18-20 May 2003, Huntington Beach, CA, USA, pp. 1-8

Gens A, Alonso E (1992) A framework for the behaviour of unsaturated expansive clays. Can Geotech J 29:1013-1032

Hu Y, Chowdhully R, Azam S (2010) Behaviour of Expansive Soils at a Water Distribution Pipe Site. In: Proceedings, 63rd Canadian Geotechnical Conference, Calgary, AB, Canada, 12-16 September 2010, pp.1426-1434

Ito M, Azam S (2009) Engineering characteristics of a glacio-lacustrine clay deposit in a semi-arid climate. B Eng Geol Environ 68:551-557

Ito M, Azam S (2013) Engineering properties of a vertisolic expansive soil deposit. Eng Geol 152:10-16

Ito M, Hu Y (2011) Prediction of the Behaviour of Expansive Soils. Proceedings, $64^{\text {th }}$ Canadian Geotechnical Conference and $14^{\text {th }}$ Pan-American Conference on Soil Mechanics and Geotechnical Engineering, 2-6 October 2011, Toronto, ON, Canada. 470: pp 1-8

Jotisankasa A, Vadhanabhuti B, Lousuphap K, Sawangsuriya A (2011) Mechanisms of Longitudinal Cracks Along Pavement Shoulder in Central Thailand. In: Jotisankasa A, Sawangsuriya A, Soralump S, Mairaing W (eds) Unsaturated Soils. Theory and practice, Thailand, pp 699-705

Lu N, Likos WJ (2004) Unsaturated Soil Mechanics. Wiley, NY, USA

McKnight T, Hess D (2001) Physical Geography: A Landscape Appreciation, 7th edn. Prentice-Hall, Inc, Englewood Cliffs, NJ, USA

Phanikumar B, Sharma R (2006) An Innovative Foundation Technique for Expansive Soils (1 ed.). In: Al-Rawas A, Goosen M (eds) Expansive Soils: Recent Advances in Characterization and Treatment. Tayler and Francis, London, UK, pp 507-521

Roscoe K, Schofield AN, Wroth CP (1958) On the yielding of soils. Geotechnique $8(1): 22-53$

Roscoe K, Burland J (1968) On the Generalized Stress-Strain Behaviour of the wet Clay. In: Heyman J, Leckie F (eds) Engineering Plasticity. Cambridge University Press, Cambridge, UK, pp 535-609

Shah I (2011) Swelling Properties of an Unsaturated Expansive Soil Deposit. M.A. Sc. Thesis, University of Regina.

van de Griend AA, Owe M (1994) Bare soil surface resistance to evaporation by vapor diffusion under semiarid conditions. Water Resour Res 30:181-188

Vanapalli SK, Oh WT (2010) A model for predicting the modulus of elasticity of unsaturated soils using the soil-water characteristic curve. J Geotechn Eng 4(4):425-433

Vu H, Fredlund D (2004) The prediction of one-two-, and three-dimensional heave in expansive soils. Can Geotech J 41:713-737 
Vu H, Hu Y, Fredlund D (2007) Analysis of Soil Suction Changes in Expansive Regina Clay. In: Proceedings. 60 ${ }^{\text {th }}$ Canadian Geotechnical Conference, 21-24 October 2007, Ottawa, ON, Canada, pp.1069-1076

Wilson GW (1997) Surface Flux Boundary Modeling for Unsaturated Soils. In: Unsaturated Soils Engineering Practice, Geotechnical Special Publication No. 68, ASCE, pp. 38-65

Zhan T, Ng C, Fredlund D (2007) Field study of rainfall infiltration into a grassed unsaturated expansive soil slope. Can Geotech J 44:92-408

doi:10.1186/s40068-014-0019-5

Cite this article as: Ito et al:: A two stage model for moisture-induced deformations in expansive soils. Environmental Systems Research 2014 3:19.

Submit your manuscript to a SpringerOpen ${ }^{\circ}$ journal and benefit from:

- Convenient online submission

- Rigorous peer review

- Immediate publication on acceptance

- Open access: articles freely available online

- High visibility within the field

- Retaining the copyright to your article

Submit your next manuscript at $\gg$ springeropen.com 